\title{
Science of Psychology as a Tool for Islamic Revival
}

\author{
Mohammad Mushfequr Rahman \\ Department of Psychology, University of Derby, Derby, UK
}

\section{Email address:}

100438290@unimail.derby.ac.uk

\section{To cite this article:}

Mohammad Mushfequr Rahman. Science of Psychology as a Tool for Islamic Revival. American Journal of Applied Psychology. Vol. 11, No. 1, 2022, pp. 9-16. doi: 10.11648/j.ajap.20221101.12

Received: December 24, 2021; Accepted: January 8, 2022; Published: January 15, 2022

\begin{abstract}
As psychology is the scientific study of mind and behavior then it follows that psychology should be able to understand, manipulate, predict and treat human thought and behavior. The purpose of this paper is to explain how first of these three could be used to revive Islam among Muslims in Muslim majority countries. The discussion has been analytical in nature while applying psychological principles and theories from a wide range of psychological studies to understand and design Islamic revival. The paper focuses on five core psychological and psychosocial areas: early childhood development, adulthood, social relationship, marriage and unity. These are crucial foundations for any people, society and it's worldview and even more so for Muslims and Islamic revival. The readers must not in anyway, get the idea that this paper proposes Islam vs West conflict, rather the paper establishes the uniqueness and independence of the Islamic society through the Islamic religion while revealing Islam as a broader system. The paper truly establishes human diversity on independent values and laws through Islam as an example. The paper reveals that psychology is a workable science and not just theory and as such Muslim psychologists should continue to study and use psychology to evolve and mature the Islamic self-concept, Islamic conscience and Islamic society.
\end{abstract}

Keywords: Applied Psychology, Early Childhood Development, Adulthood, Social Relationship, Marriage, Unity, Islam and Psychology

\section{Introduction}

This paper applies current psychological theories in five core psychological and psychosocial areas: early childhood development, adulthood, social relationship, marriage, and unity to develop the Islamic self-concept, Islamic conscience and Islamic society. The discussion starts on the importance of achieving the Islamic self-concept. Favorable groundwork should be created to initiate the realization, evolution, and maturity of the Islamic self-concept. Once it is in the process of development other psychological and psychosocial aspects can be addressed. Once the developmental and maturing journey starts an inertia may accumulate and steer these in a coherent and systematic way.

The subject of how psychology can be applied to Islamic revival is important for Muslims to utilize and benefit from Islam and helping them see how Islam is a broader system of life. Many readers have the idea that psychology is a secular science and there is no place for religion in it. Science is neither secular nor religious but a tool to understand existence and used to achieve individual and social benefits, among other things. This paper will help the reader understand that Islam provides guidance and protocols to sufficiently address those five concerns as mentioned previously through psychology.

\section{Method}

The paper has identified, selected and critically appraised many relevant psychological research, and analyzed data from these studies to answer the question: can psychology as a science be used to make Islam functional?

\section{Result}

Islam gives a detailed blueprint for the five concerns mentioned in the abstract and introduction. Science of psychology can be used to design, implement and realize the Islamic equivalence of these five concerns.

One interesting observation can be also made from the discussion is if we have absolute free will or is our ability to 
choose often guided by some underlying principles from which we often may not deviate? These principles are rooted in genetics, biological and cultural aspects. Culturally it can be termed as the first choice which is the foundational worldview of an individual under which psychology works in predicting human behavior. If our free will was totally random without these foundations, we could not have discovered many psychological theories. In order to apply psychology and discover new psychology these foundational principles need to be targeted.

\section{Discussion}

\subsection{The Need for Islamic Self Concept}

The self is the most important place for any changes to be realized. There is no collectivism without the self. Psychologically the self is a continuous revelation of various mental and behavioral states. The two most important of these states are consciousness ${ }^{1}$ and selfconcept ${ }^{2}$. In order for the wide reaching in depth Islamic revival to commence the Muslim self must realize the Islamic self-concept once he has realized he exists in this world as a discrete entity of human species. Trend, populism and the feeling that "what people will think" are impeding full realization of Islamic self-concept both for the Muslim individual and the Muslim collective in any capacity. Today Muslim self-concept is a cocktail of Islamic and non-Islamic world views and culture. Habits associated with certain thoughts and behavior are also an impedance for Muslim adherence to Islam. This is why Islamic selfconcept among Muslims is polluted and when these Muslims come to know other aspects of Islam which their current self-concept do not contain, they become discontent with Islam but to justify their self-deceived loyalty to Islam they create illusions by misinterpretation of Islam. The misinterpretation occurs through cognitive bias $^{3}$ because of confirmation bias ${ }^{4}$ to achieve liberal secular conformity ${ }^{5}$.

\subsection{What Is Islamic Self-Concept}

Self-concept through Islam means defining and being able to perceive and practice thoughts and behavior through the guidance of Islam as found in the Islamic texts and it's deductions. Muslims in order to achieve self-concept must detach and reshape their minds. This can be achieved by placing Islam in a time and place which did not have liberalism, secularism, and democracy. This will help the psychology of the Muslim to revert back to the era of Islamic

\footnotetext{
1 Our subjective awareness of ourselves and our environment through sense experience and interpretation of such called sense perception.

2 Content of the consciousness. Self-concept contributes to the individual's sense of identity over time.

3 Errors in memory or judgment that are caused by the inappropriate use of cognitive processes

4 The tendency to search for, interpret, favor, and recall information in a way that confirms or supports one's prior beliefs or values.

5 Change in beliefs or behavior that occurs as the result of the presence of the other people around us.
}

justice mainly in the Prophetic times, times of Imam Ali and prosperity dominated by Islam such as the Islamic golden age. For some Muslims this may result initially in cognitive dissonance ${ }^{6}$ but through time by law, social rules, education, understanding and hopeful future vision this new reality of Islamic realization will be habituated ${ }^{7}$. This must not be interpreted as Islam vs West but rather seen as distinction of Islam from other ideologies of the world.

As Muslims under the new Islamic reality faces challenges of Islamic development for survival and maturing, these evolutionary needs often enhanced by religious inspiration will create drive in them and will reduce their emotional and physical pains as people feel less pain when they are busy focusing on a challenging activity [1]. This challenging activity for the Muslims will be to develop, mature and sustain Islamic rule and Islamic society. As Islamic rule matures, and the Islamic society and economy develops and as we experience more and more positive outcomes in our daily lives, we habituate to them and as a result our life satisfaction will return to a more moderate level [2] under Islamic rule and in Islamic society. The realization of Islamic rule, Islamic society through Islamic self-concept of the Muslim is essential to long term Islamic unity and solidifying Islamic revival because Islamic interpersonal attraction, or what makes people like, and even love each other is a perceived similarity in values and beliefs between the partners [3] achieved through Islamic beliefs and values safeguarded by Islamic rule.

\subsection{Psychological and Social Preparation}

People may achieve some mental good if they try to forget something bad and in case of Muslims the aim is to achieve hope through Islam and forget the negative aspects of liberalism, secularism, and democracy and what comes with it such as failure of Muslims in politics, economy and science for example. This erasure of these modern ideologies does not imply Islam is hostile to west, rather erasure is a psychological and Islamic demand due to mainly Islam being fundamentally different from these modern concepts. This separation of humanity based on beliefs and values is what make humanity diverse, and perhaps necessary due to mankind being evolutionarily disposed to stereotyping because our primitive ancestors needed to accurately separate members of their own kin group from those of others, categorizing people into "us" (the ingroup) and "them" (the outgroup) was useful and even necessary [4]. This is also necessary for Muslims to preserve their Islamic identity.

In order to completely achieve the Islamic self-concept, we must learn our religion Islam and practice it. Islamic selfconcept is achieved through acquaintance, adoption and practice of divine obligations and prohibitions. A Muslim

\footnotetext{
6 Refers to the discomfort we experience when we choose to behave in ways that we see as inappropriate

7 Refers to the decreased responsiveness toward a stimulus after it has been presented numerous times in succession.
} 
may say that achieving such is difficult due to the enormity of Islamic guidance. This confusion is addressed by the concepts of general theme and specific theme. The general theme consists of all commands and prohibitions which every adult Muslim must adhere by while the specific theme addresses various social roles and functional capacities which a Muslim or a group of Muslim must adhere by when they participate in such roles and capacities.

In order to achieve extensive Muslim participation in Islam Muslims must know how Islam addresses their respective functional capacities and social roles. What we need is to create guidebooks containing guidelines. These guidebooks will act as protocol books containing briefly the essential rules of various functional capacities that the Muslim may involve in. For example, an individual in an Islamic jurisdiction may be a husband, a housewife, a businessman, an employee, a policeman, a doctor or even a student etc. Islam gives textual and derived guidance for such roles and responsibilities.

What Islamic government should do is put this guidance in relevant guidebooks and distribute through important distribution points such as mosque, supermarkets, malls etc. or through the relevant place of work for the relevant people and also online. If Muslims are able to see a summary of the essentials of his or her social role and functional capacity, it will help them adhere to Islam thereby actually making Islam socially functional. This is a way of helping Islamic society adhere to Islam and continue its functionalism. This is workable because the situation is the most powerful determinant of conformity and authority creates more conformity [5] which in this case is the Islamic situation of the society brought about by the Islamic authority through Islamic rule.

Why do Muslims need to realize Islamic self-concept? This is important to eradicate the inferiority complex inherited from colonialism and sustained through current neocolonialism. Inferiority complex ${ }^{8}$ has been enforced from associating liberal secular culture with technological and economic success, so Muslims see no reason to appeal to Islam wholescale, but many Muslims still adhere to very minimum of Islam such as rituals and God's existence because it gives them some meaning in life, or it associates attachment with their ancestors. A wholescale adherence to Islam will achieve greater epistemic and cultural achievement but this has been suppressed or hidden from the Muslim conscience. The reason early Muslims during colonialism were engulfed by inferiority complex was due to lack of Islamic success and overwhelming grip of European colonialism and European epistemic success. This is because inferiority complex creates a basic feeling of inadequacy and insecurity, deriving from actual or imagined physical or psychological deficiency. Muslims during colonialism, in order to escape this inferiority complex took two pathways according to the theory of inferiority complex: complete

8 A basic feeling of inadequacy and insecurity, deriving from actual or imagined physical or psychological deficiency. withdrawal as happened with the religious Muslims who are still withdrawn from politics or overcompensation of excessive competition that had happened in early Muslim governments who tried to westernize traditional Muslim society by force [6]. Muslims still today are suffering from inferiority complex and that is why they may be afraid of Islamization.

\subsection{How to Develop Islamic Self-concept}

Self-concept starts in development and is sustained through ongoing social process. This development of the individual is known as nurture or environmental fashioning. Along with genetics nurture also plays a huge role in fashioning the individual's cognitive [7, 8] and behavioral aspects $[9,10]$. Two important fields of psychology are then useful to achieve and sustain Islamic self-concept: Developmental psychology and social psychology. Development starts in the womb of the mother, but the most important stages of developments are childhood and adolescence whereas the ongoing social process should be channeled to the adult and old periods. From childhood to adolescence the knowledge and skills of the child is achieved as it interacts with the objects in the environment. This environment in the liberal society contains many of the Islamically prohibited occurrences and behavior which impedes and erodes the realization of Islamic self-concept. Also, the important thing the child learns from the environment is schemas and deduction using such schemas so the Islamic rule and Islamic society thus must fashion this environment on the guidance of Islamic law and Islamic values.

Between the childhood and adolescence, the prefrontal cortex, the area of the brain responsible for reasoning, planning, and problem solving, also continues to develop [11]. Also, it has been hypothesized that adolescents may engage in risky behavior, such as smoking, drug use, dangerous driving, and unprotected sex in part because they have not yet fully acquired the mental ability to curb impulsive behavior or to make entirely rational judgments [12]. Part of Islamizing the environment is to prohibit all these pathways to impulsive behavior and irrational judgements so that reasoning, planning, and problemsolving abilities are developed fluently without emotional and physiological impedance. Young children are most strongly attached to their parents but the important attachments of adolescents move increasingly away from parents and increasingly toward peers [13]. The Islamic environment brought about by Islamic rule will ensure the friendship formed in various social institutions especially schools and colleges follow Islamic protocols and Islamic attitude, and that such friendship act as unity towards a higher purpose and betterment of the society rather than hedonistic impulses.

Islamic development of the individual must target James Marcia's stages of identity development. The Islamic education and upbringing must show the Islamic identity of the individual under God, a moral agent with responsibility 
towards the self and others. Whenever the individual is choosing a purpose and identity the Islamic society should make sure no misguided purpose and identity are accessed and considered by the individual, so this means the Islamic society is to be regulated on rational freedom of the individuals. The individual in the Islamic society, based on relevant gender, should realize their roles and responsibilities in relation to God and in relation to each other such that patriarchy is enforced, and marriage and motherhood are encouraged. Social identity is an important part of the selfconcept that is also derived from group membership so Islamic environment (nurture) must ensure valid purposive constructive groups are formed in all levels of social institutions and social activities.

Islamic environment should target the individual's moral reasoning through Lawrence Kohlberg's stages of moral reasoning. These stages should be fashioned on the basis of Islamic environment. The moral development starts in the childhood, so the most important environmental factors are parents and close social relationship. It is thus extremely important that this domain of environmental effects have realized their Islamic self-concept to affect sufficiently the children. As the individual develops Islamic philosophical moral reasoning should be taught so that the individual can approach morality through reason and religion rather than trend and populism. One of many reasons why Islam allowed child marriage is possibly due to the Islamic patriarch greatly contributing to the development of the Islamic female by guidance, finance and protection.

We thus far have understood that the period between childhood and puberty is extremely important to build the moral, cognitive and judgmental foundations of the individual and that in this period the individual seeks to form a self-identity ${ }^{9}$ which is affected immensely by the formation of the self-concept. It then follows that if this period, this journey of the individual is not guided on consistent education and upbringing the foundations may not form properly and self-identity may be self-conflicting. This is a major reason why age rating has been adopted in western societies. So Islamic society must ensure that non-Islamic conflicting and contradictory world views are eradicated from the individual's upbringing and education through Islamic legislation and social institutional protocols, i.e., in other words Islamic age rating should be strictly enforced. Today Muslim societies due to failure to implement this period of development properly have resulted in polluted Islamic self-concept. For example, Muslim females have polluted the properness of Hijab by sexualized looks. This sexualization of Hijab arises from adopting part of liberal feminine self-concept as Fredrickson and colleagues concluded that women like to objectify themselves specially how they look and display themselves [14]. Another example

9 An individual's sense of self defined by (a) a set of physical, psychological, and interpersonal characteristics that is not wholly shared with any other person and (b) a range of affiliations (e.g., ethnicity) and social roles. Identity involves a sense of continuity, or the feeling that one is the same person today that one was yesterday or last year (despite physical or other changes). is that Muslim females have unconsciously or consciously adopted feminism by falsely attributing Islam with feminism and thereby creating familial conflicts and divorce especially when the Islamic male desires a traditional Islamic woman in the Muslim female as per dictates of Islamic texts and Islamic historical practice. The examples of Islamic selfconcept having been polluted by improper ineffective development of the individual are thus many.

As the individual enters adulthood Islamically he or she becomes responsible and all duties and responsibilities relevant to that individual becomes active. The most important Islamic duty is realized in adulthood i.e., Islamic income which rejects income by dishonesty, cheat, fraud and prohibited means. Adulthood is what defines the core of Islamic society. Adulthood is the pool from where the Islamic human capital is formed so this is extremely important guiding period of the Islamic society. Rulers, soldiers, policemen, scientists, doctors, teachers, engineers and many other intellectuals who have developed Islamic self-identity in early period of their lives must now show how they utilize this towards Islamic empowerment to the full extent. Adulthood may demand changes in personality and attitude depending on the social role and functional capacity of the individual and as research has found that the people who are best able to adjust well to changing situations early in life are also able to better adjust later in life [15] so if Islamic upbringing is effectively implemented and Islamic law and guidance is ruling the society then such adjustments become harmonious as the Islamic self-concept and social changes demanding adjustment are mutually supportive. As adulthood enters old age the Islamic society must ensure proper care [16] for the old people through various activities and social involvement because although physical illnesses may occur to anyone, the more people keep their brains active and the more they maintain a healthy and active lifestyle, the healthier their brains will remain [17]. It must also ensure proper retirement for old people with just and fair pension and Islamic government support.

\subsection{The Importance of Marriage}

Marriage is an important institution and practice in the Islamic society unlike the secular society [18]. Marriage is no more a primary relationship in liberal secular society rather sex has become the primary relationship between a man and woman and as long as this relationship is shared by both sexes, they don't experience the context of long-term commitment and continuous relationship which would demand a form of hierarchy. Even the marriages among many in liberal societies continue on the basis of frequent joy they engage in together but whenever loyalty, devotion and self-sacrifice are needed distance between the couple is revealed and rivalry emerges [19, 20]. Feminism is thus a self-deceiving acceptance of liberal society whose harms are revealed situationally with great damage in relationship and intensifying hostilities between the genders.

Early marriage in west is prohibited because western cultural upbringing sees early marriage as immature and 
irresponsible. For example, western adolescent mothers are more likely to use drugs and alcohol during their pregnancies, to have poor parenting skills in general, and to provide insufficient support for the child [21] and as a result, the babies of adolescent mothers have higher rates of academic failure, delinquency, and incarceration in comparison to children of older mothers [22]. This need not be the case in Islamic society where self-identity through Islam has been greatly infused through early development and that access to prohibited consumptions are not allowed and also patriarchy has been obligated to care and protect the females. Early marriage will also fashion heterosexual orientation due to the nature of early childhood sexuality and its formation in relation to the environment [23].

\subsection{The Preservation of Sexual Morality}

The Islamic society adopts the rule of Hijab or feminine Islamic clothing and segregated system. This arises from sex differences between man and woman. While sexual desire of women is extremely sensitive to environment, social and cultural factors and is more contextual, more subjective, more layered on a lattice of emotion men's sexuality is direct because men think of sex more, vividly and men are visual [24]. This means as soon as the feminine lust-inspiring image registers in their brain, they become turned-on, not only physically but psychologically, too. Psychologically the sexual triggers for men are depiction of women (in stills or, even better, in videos) gasping, moaning, screaming, and swooning. Also, men's brains are designed to objectify females [25]. Considering these sex differences in sexual desire Islamic hijab is a filter and preventive mechanism so that men can control themselves thereby facilitating efficiency and effectiveness of spiritual, functional and intellectual aptitudes. The Islamic protocols will also reduce and even prevent sexual crimes and sexual perversions by controlling sexual desires of the both sexes.

\subsection{Building Relationship}

Islamic social relationship is built on similarity of Islamic values. People who report that they have positive social relationships with others - the perception of social support - also report being happier than those who report having less social support [26] and as similarity influences those who we help [27] and as people who are connected with and accepted by others suffer less depression, higher self-esteem, and less social anxiety and jealousy than those who feel more isolated and rejected [28] then it follows that Islamic brotherhood and sisterhood is crucial in creating social cohesion. There are numerous Islamic texts which emphasizes brotherhood and self-sacrifice on shared Islamic faith rejecting tribalism, racism and nationalism. While building and maintaining Islamic relationship, according to Islamic texts, a believer should be a mirror to another believer so it follows that we should remind each other of Islamic values when we see and greet each other. In the least we should not remind each other of something which is discouraged by Islam. This is because the physical features of other people are very salient, and we often focus our attention on these dimensions [29].

\subsection{Prejudice, Stereotyping and Discrimination}

The Islamic character and the Islamic society reject irrational stereotyping of anyone because our stereotypes lead us to treat people differently and often unjustly. For example, in secular societies the physically attractive are given better grades on essay exams, are more successful on job interviews, and receive lighter sentences in court judgments than their less attractive counterparts [30]. However, if stereotyping is based on reason and justice such as Islamic prohibition of judging anyone by looks, wealth or class, while judging someone on the nature of one's moral compass, values and actions then one can use valid stereotyping for decision making in relevant decision points of life. Just as justified discrimination is acceptable justified stereotyping is too acceptable. It is wrong to equate stereotyping, prejudice and discrimination. While prejudice is always wrong the other two are not always wrong. For example, if there is cultural evidence that a certain group is statistically racist then we should practice stereotyping towards that group in relevant social participation by that ethnicity which would require practicing stereotyping at that point of participation. Would American law or authority appoint a US supreme court justice from the KKK group? So Muslims must be sincere in their judgements because judgement is often needed and is possible as research has demonstrated that people can draw very accurate conclusions about others on the basis of very limited data [31] and that people are reasonably accurate in their attributions. However, at certain psychological states we must avoid judgement such as when we are tired, distracted, or busy doing other things [32, 33].

\subsection{The Requirements of Unity}

One of the most powerful mental instruments towards any unity, including Islamic unity, is conformity ${ }^{10}$. The typical outcome of conformity is that our beliefs and behaviors become more similar to those of others around us. Today liberalism and secular democracy are defining social conformity in almost all societies of the world including Muslim ones. Islamic society must target the variables which increase and maintain Islamic conformity [34] such as a) majority Islamic rule as the number of people who are engaging in a behavior increases, the tendency to conform to those people also increases $b$ ) high unanimity as conformity reduces sharply when any one person deviates from the norm and lastly c) status and authority of Islam as people who have higher status, such as those in authority, create more conformity [5]. These three features of unity must be realized in Muslim countries to achieve Islamic rule and Islamic society, or else minority views become majority such as how secularism has engulfed once traditional Islamic societies of

10 A change in beliefs or behaviour that occurs as the result of the presence of the other people around us. 
the world. This is because minorities who are consistent and confident in their opinions may in some cases be able to be persuasive [35].

Applying the concepts of conformity, we can take the example of Malaysia which calls itself a Muslim and Islamic country however this is not the case as the three requirements of unity have not been fulfilled among the Muslim majority in Malaysia and that the minority non-Muslims are consistent and confident in their opinions having strong influence against Islamic rule. As there is lack of conformity among Muslims in Malaysia so it results in lack of unity which in turn results in lack of group performance, political or otherwise, impeding Islamic motivation to meet the group goals, effectively sharing information, and efficiently coordinating their efforts.

However Islamic conformity does not mean irrational unity as happens with nationalism and racism where ethnicity is the unifying factor and acts as the agent of conformity. We know how this blind conformity has created the cruelest of human behavior against outgroups. Islamic conformity is based on reason and justice which are the two pillars of Islamic religion. So, the benefit of Islamic unity in the sense of group unity is efficient process and strong conformity in this process on reason and justice. The purpose of Islamic conformity is to achieve justice on earth on behalf of God. If Islamic conformity fails to adopt reason and justice as it's pillars of guidance, [36] then the Islamic group can fail as a result of a flawed group process where even expert members unwilling to seek out or discuss discrepant or unsettling information about the topic at hand and the group members do not express contradictory opinions. Islamic group process remedies this by obligating expression of truth even against oneself, rewarding good and merit, being direct and honest and practicing collaboration and clear communication of information [36]. In the group setting this will mean express true views even if they are uncomfortable.

Applying this psychological reality in the Malaysian context imagine if Muslim politicians there were united and applied these principles of group process it would not only enhance Islamic unity but break minority non-Muslim conformity against Islamic rule. However, the reality is Muslim politicians of Malaysia including the royalties practice high levels of ethnic conformity based on Malay supremacy, but this blinds them on irrationality and against Islamic demands. This makes them overvalue the productivity of their dominant Malay group and this gives the impression that the Malay group is doing very well, even if objectively it is not.

\section{Conclusion}

The subject of how psychology can be applied to Islamic revival is important for Muslims to utilize and benefit from Islam and helping them see how Islam is a broader system of life.

The self is the most important place for any changes to be realized. Self-concept through Islam means defining and being able to perceive and practice thoughts and behavior through the guidance of Islam as found in the Islamic texts and it's deductions. In order to completely achieve the Islamic self-concept, we must learn our religion Islam and practice it. Islamic self-concept is achieved through acquaintance, adoption and practice of divine obligations and prohibitions. Muslims must develop a sense of strong ingroup based on Islam.

Self-concept starts in development and is sustained through ongoing social process. This development of the individual is known as nurture or environmental fashioning. Two important fields of psychology are then useful to achieve and sustain Islamic self-concept: Developmental psychology and social psychology.

Islamic development of the individual must target James Marcia's stages of identity development. Islamic environment should target the individual's moral reasoning through Lawrence Kohlberg's stages of moral reasoning. The period between childhood and puberty is extremely important to build the moral, cognitive and judgmental foundations of the individual and that in this period the individual seeks to form a self-identity. It then follows that if this period, this journey of the individual is not guided on consistent education and upbringing the foundations may not form properly and self-identity may be self-conflicting.

While Feminism is a self-deceiving acceptance of liberal society whose harms are revealed situationally with great damage in relationship and intensifying hostilities between the genders Islamic marriage and family is based on realizing proper gender positions, roles, duties and responsibilities to create intense harmony emanating from Islamic self-concept.

The Islamic society implements sexual morality, rejects prejudice and utilizes justified rational discrimination and stereotyping.

The Islamic society achieves and maintains unity on the basis of reason and justice through majority unity of Muslims and sympathetic non-Muslims, high unanimity of these people implemented through status and authority of Islam.

In conclusion we can see how science of psychology can be used to empower Islam, Islamic rule and Islamic society by targeting the Muslim mind and behavior based on these psychological principles. The focal points that need to be fashioned are the developmental stage, the ongoing social processes, adulthood, the institution of marriage and the political and group unity.

\section{Recommendation}

Muslim governments and Muslim societies must use principles and theories of psychology to best achieve Islamic reality in Muslim countries and thereby erasing the notion that Islam is a failed religion and Muslims are backwards because of Islamic adherence. It is also in the best interest of Islam that Muslim psychologists continue to focus their research into these stages so that Islamic reality is evolved effectively and strongly sustained long term. 


\section{References}

[1] Bantick, S. J., Wise, R. G., Ploghaus, A., Clare, S., Smith, S M., \& Tracey, I. (2002). Imaging how attention modulates pain in humans using functional MRI. Brain: A Journal of Neurology, 125 (2), 310-319.

[2] Small, D. M., Zatorre, R. J., Dagher, A., Evans, A. C., \& Jones-Gotman, M. (2001). Changes in brain activity related to eating chocolate: From pleasure to aversion. Brain, 124 (9), $1720-1733$

[3] Davis, J. L., \& Rusbult, C. E. (2001). Attitude alignment in close relationships. Journal of Personality \& Social Psychology, 81 (1), 65-84.

[4] Neuberg, S. L., Kenrick, D. T., \& Schaller, M. (2010). Evolutionary social psychology. In S. T. Fiske, D. T. Gilbert, \& G. Lindzey (Eds.), Handbook of social psychology (5th ed., Vol. 2, pp. 761-796). Hoboken, NJ: John Wiley \& Sons.

[5] Milgram, S. (1974). Obedience to authority: An experimental view. New York, NY: Harper and Row.

[6] dictionary.apa.org. (n.d.). APA Dictionary of Psychology. [online] Available at: https://dictionary.apa.org/inferioritycomplex.

[7] Cole, M. (1996). Culture in mind. Cambridge, MA: Harvard University Press; Rogoff, B. (1990). Apprenticeship in thinking: Cognitive development in social context. New York, NY: Oxford University Press;

[8] Tomasello, M. (1999). The cultural origins of human cognition. Cambridge, MA: Harvard University Press.

[9] Gibson, E. J., Rosenzweig, M. R., \& Porter, L. W. (1988). Exploratory behavior in the development of perceiving, acting, and the acquiring of knowledge. In Annual review of psychology (Vol. 39, pp. 1-41). Palo Alto, CA: Annual Reviews.

[10] Smith, L. B., \& Thelen, E. (2003). Development as a dynamic system. Trends in Cognitive Sciences, 7 (8), 343-348.

[11] Goldberg, E. (2001). The executive brain: Frontal lobes and the civilized mind. New York, NY: Oxford University Press.

[12] Steinberg, L. (2007). Risk taking in adolescence: New perspectives from brain and behavioral science. Current Directions in Psychological Science, 16, 55-59.

[13] Harris, J. (1998), The nurture assumption -Why children turn out the way they do. New York, NY: Free Press.

[14] Fredrickson, B. L., Roberts, T.-A., Noll, S. M., Quinn, D. M. and Twenge, J. M. (1998). "That swimsuit becomes you: Sex differences in self-objectification, restrained eating, and math performance": Correction to Fredrickson et al. (1998). Journal of Personality and Social Psychology, 75 (5), pp. 1098-1098.

[15] Rubin, L. (2007). 60 on up: The truth about aging in America. Boston, MA: Beacon Press; Sroufe, L. A., Collins, W. A., Egeland, B., \& Carlson, E. A. (2009). The development of the person: The Minnesota study of risk and adaptation from birth to adulthood. New York, NY: Guilford Press.

[16] Rahman, M. M. (2020). The Islamic Society: The Sociological Perspective. www.academia.edu, [online] pp. 63-67. Available
https://www.academia.edu/45005183/The_Islamic_Society_T he_Sociological_Perspective.

[17] Ertel, K. A., Glymour, M. M., \& Berkman, L. F. (2008). Effects of social integration on preserving memory function in a nationally representative U.S. elderly population. American Journal of Public Health, 98, 1215-1220.

[18] Rahman, M. M. (2020). The Islamic Society: The Sociological Perspective. www.academia.edu, [online] pp. 97-112. Available at: https://www.academia.edu/45005183/The_Islamic_Society_T he_Sociological_Perspective.

[19] Scott, S. B., Rhoades, G. K., Stanley, S. M., Allen, E. S. and Markman, H. J. (2013). Reasons for divorce and recollections of premarital intervention: Implications for improving relationship education. Couple and Family Psychology: Research and Practice, [online] 2 (2), pp. 131-145. Available at: https://www.ncbi.nlm.nih.gov/pmc/articles/PMC4012696/.

[20] Davis, B. and Aron, A. (1989). Perceived Causes of Divorce and Postdivorce Adjustment Among Recently Divorced Midlife Women. Journal of Divorce, 12 (1), pp. 41-55.

[21] Ekéus, C., Christensson, K., \& Hjern, A. (2004). Unintentional and violent injuries among pre-school children of teenage mothers in Sweden: A national cohort study. Journal of Epidemiology and Community Health, 58 (8), 680-685.

[22] Moore, M. R., \& Brooks-Gunn, J. (2002). Adolescent parenthood. In M. H. Bornstein (Ed.), Handbook of parenting: Being and becoming a parent (2nd ed., Vol. 3, pp. 173-214). Mahwah, NJ: Lawrence Erlbaum Associates.

[23] Rahman, M. M. (2020a). Is Homosexuality Acquired or Inherent. www.academia.edu. [online] Available at: https://www.academia.edu/49286591/Is_Homosexuality_Acq uired_or_Inherent.

[24] Sine, R. (2009). Sex Drive: How Do Men and Women Compare? [online] WebMD. Available at: https://www.webmd.com/sex/features/sex-drive-how-do-menwomen-compare.

[25] Ogas, O., \& Gaddam, S. (2011). A billion wicked thoughts: What the world's largest experiment reveals about human desire. Dutton/Penguin Books.

[26] Diener, E., Suh, E. M., Lucas, R. E., \& Smith, H. L. (1999). Subjective well-being: Three decades of progress. Psychological Bulletin, 125 (2), 276-302.

[27] van Baaren, R. B., Holland, R. W., Kawakami, K., \& van Knippenberg, A. (2004). Mimicry and prosocial behavior. Psychological Science, 15 (1), 71-74.

[28] Leary, M. R. (1990). Responses to social exclusion: Social anxiety, jealousy, loneliness, depression, and low self-esteem. Journal of Social and Clinical Psychology, 9 (2), 221-229.

[29] Zebrowitz, L. A., \& Montepare, J. (2006). The ecological approach to person perception: Evolutionary roots and contemporary offshoots. In M. Schaller, J. A. Simpson, \& D. T. Kenrick (Eds.), Evolution and social psychology (pp. 81113). Madison, CT: Psychosocial Press.

[30] Hosoda, M., Stone-Romero, E. F., \& Coats, G. (2003). The effects of physical attractiveness on job-related outcomes: A meta-analysis of experimental studies. Personnel Psychology, $56(2), 431-462$. 
[31] Ambady, N., \& Rosenthal, R. (1993). Half a minute: Predicting teacher evaluations from thin slices of nonverbal behavior and physical attractiveness. Journal of Personality \& Social Psychology, 64 (3), 431-441.

[32] Trope, Y., \& Alfieri, T. (1997). Effortfulness and flexibility of dispositional judgment processes. Journal of Personality and Social Psychology, 73 (4), 662-674.

[33] Bodenhausen, G. V. (1990). Stereotypes as judgmental heuristics: Evidence of circadian variations in discrimination. Psychological Science, 1, 319-322.
[34] Milgram, S., Bickman, L., \& Berkowitz, L. (1969). Note on the drawing power of crowds of different size. Journal of Personality and Social Psychology, 13, 79-82.

[35] Moscovici, S., Mugny, G., \& Van Avermaet, E. (1985). Perspectives on minority influence. New York, NY: Cambridge University Press.

[36] Rahman, M. M. (2021). Political and Legal System of Islam. www.academia.edu, [online] pp. 17-26. Available at: https://www.academia.edu/60559324/Political_and_Legal_Sy stem_of_Islam. 